\title{
FAKTOR-FAKTOR PEMILIK BANGUNAN TIDAK MENGURUS IZIN MENDIRIKAN BANGUNAN DI KOTA BUKITTINGGI
}

\author{
Aini Khalid ${ }^{1}$, Ahyuni $^{2}$, Febriandi ${ }^{2}$ \\ Program Studi Geografi \\ Fakultas Ilmu Sosial Universitas Negeri Padang \\ Email: ainikhalid5@gmail.com
}

\begin{abstract}
Abstrak
Penelitian ini membahas tentang faktor-faktor pemilik bangunan tidak mengurus izin mendirikan bangunan di Kota Bukittinggi. Data yang digunakan yaitu data primer dan data sekunder .Sampel dalam penelitian ini adalah pemilik bangunan yang tidak mengurus izin mendirikan bangunan di Kota Bukittinggi dengan jumlah populasi 285 dan sampel yaitu sebanyak 74 orang. Penelitian ini dilaksanakan dengan cara pengumpulkan data secara observasi, wawancara dan kuisioner dengan metode delphi sebagai teknik analisis. Diperoleh hasil bahwa terdapat 5 faktor yang mempengaruhi pemilik bangunan tidak mengurus izin mendirikan bangunan di Kota Bukittinggi yaitu tidak tahu aturan IMB, tidak ada biaya untuk mengurus IMB, pengurusan IMB lama dan prosedur yang sulit, tidak cukup persyaratan administrasi dan tidak ada waktu untuk mengurus IMB. Adapun faktor yang paling berpengaruh yang dirasakan oleh pemilik bangunan adalah tidak ada biaya untuk mengurus izin mendirikan bangunan.Kendala dalam pengurusan IMB adalah 1) Masyarakat tidak paham mengenai prosedur, 2) Ketidaksiapan masyarakat untuk membayar restribusi IMB, 3) Kesengajaan masyarakat untuk melanggar aturanaturan yang berlaku 4) keluhan tidak ada biaya, 5) IMB mahal 6) Tidak ada ketepatan waktu yang diberikan dalam pengurusan 7) masih kurangnya sosialisasi dan kurang pengawas di lapangan sehingga masih ditemukan bangunan-bangunan baru tidak memiliki izin.
\end{abstract}

Kata Kunci: Izin Mendirikan Bangunan

\begin{abstract}
This study discusses the factors of the building owner does not take care of building permit in Bukittinggi City. The sample in this research is the owner of the building that does not take care of building permit in Bukittinggi City with the population of 285 and the sample is 74 people. This research is conducted by collecting data by observation, interview and questionnaire with delphi method as analysis technique.There are 5 factors that affect the building owner does not take care of building permit in Bukittinggi City that is not know IMB rules, no fees to take care of IMB, old IMB management and procedures difficult, not enough administrative and No time to take care of IMB. The most influential factor felt by the building owner is there is no cost to take care of building permit. Constraints in the management of IMB are 1) The community does not understand the procedures, 2) the lack of public awareness to pay restribusi $I M B, 3)$ The intention of the community to violate the rules that apply from the local government to permit, 4) No cost, 5) cost of expensive IMB processing 6) No timeliness given in handling 7) Still lack of socialization and lack of supervisor in the field so it is still found new buildings do not have permission.

Key Word: Building Permit.
\end{abstract}

\footnotetext{
${ }^{1}$ Mahasiswa Program Studi Geografi untuk Wisuda September 2017

${ }^{2}$ Dosen Jurusan Geografi Fakultas Ilmu Sosial Universitas Negeri Padang
} 


\section{PENDAHULUAN}

Menurut Undang-undang nomor 24 tahun 2006, tata ruang adalah wujud struktural dari pola pemanfaatan ruang yang direncanakan maupun tidak. Kondisi penduduk secara sosial maupun ekonomi sangat terkait erat dengan penataan ruang kota, serta pengelola lingkungan dan sumber daya alam yang ada. Penataan tersebut akan berpengaruh pada sumber daya manusia yang berinteraksi dengan tempat, waktu, budaya masyarakat setempat. Dalam penataan ruang kota terdapat tiga hal yang perlu diperhatikan sebagai garis pedoman dalam menata ruang, yaitu perencanaan tata ruang, pemanfaatan, dan pengendalian pemanfaatan ruang.

Untuk pelaksanaan pembangunan tersebut diperlukan adanya ketentuan yang harus dijalankan masyarakat agar terjadi nya penataan ruang secara efektif. 1) ketentuan tata bangunan, dimana tampilan bangunan yang ditetapkan dengan mempertimbangkan bahan bangunan, serta keserasian bangunan dengan lingkungan sekitarnya. 2) pengaturan zonasi (planning), pengaturan terkait perbatasan terhadap penggunaan/pemanfaatan area atau zona yang dinilai berbahaya.

Adapun kegunaan Izin mendirikan bangunan (IMB) bagi penduduk adalah untuk kenyamanan, ketenangan lahir batin bagi pemilik rumah. Jika mendirikan rumah tidak punya IMB di saat adanya pemeriksaan/peninjauan oleh instansi yang berwenang, maka akan diberi peringatan dan secara langsung rumah tersebut dapat dibongkar tanpa izin dari pemilik rumah.

Pentingnya pengadaan bangunan berdasarkan peraturan yang berlaku khususnya di Kota Bukittinggi, serta permasalahan IMB yang terjadi dilingkungan masyarakat, penulis mencoba melakukan penelitian mengenai faktor yang menjadi dasar masyarakat tidak mengurus izin mendirikan bangunan, masyarakat memiliki andil dalam pelaksanaan peraturan pemerintah tentang izin mendirikan bangunan (IMB) tersebut, hal ini berguna untuk kemudahan masyarakat dalam Mendirikan Bangunan. Dengan hal ini penulis mencoba melakukan penelitian dengan judul "Faktor-Faktor Pemilik Bangunan Tidak Mengurus Izin Mendirikan Bangunan Di Kota Bukittinggi”.

Tujuan penelitian ini adalah untuk mengetahui faktor penyebab pemilik bangunan gedung tidak mengurus izin mendirikan bangunan di Kota Bukittinggi.

\section{Izin Mendirikan Bangunan}

Izin merupakan instrumen hukum administrasi yang dapat digunakan oleh pejabat pemerintah yang berwenang untuk mengatur caracara pengusaha menjalankan usahanya. Dalam sebuah izin pejabat yang berwenang menuangkan syaratsyarat atau ketentuan-ketentuan berupa perintah-perintah ataupun larangan-larangan yang wajib dipatuhi oleh perusahaaan. Dengan demikian izin merupakan pengaturan hukum tingkat individual atau norma hukum subjektif karena sudah dikaitkan dengan subjek hukum tertentu. Perizinan memiliki fungsi preventif dalam arti instrumen untuk pencegahan terjadinya masalahmasalah akibat kegiatan usaha. Dalam konteks hukum lingkungan, perizinan berada dalam wilayah hukum lingkungan administrasi (Rahmadi, T (2011): 105).

Dalam Peraturan Pemerintah RI no. 36 tahun 2005, izin mendirikan 
bangunan gedung adalah perizinan yang diberikan oleh pemerintah kabupaten/kota kepada pemilik bangunan gedung untuk membangun baru, mengubah, memperluas mengurangi dan merawat bangunan gedung sesuai dengan persyaratan administratif dan persyaratan teknis yang berlaku. Permohonan izin mendirikan bangunan gedung adalah permohonan yang dilakukan pemilik bangunan gedung kepada pemerintah daerah untuk mendapatkan izin mendirikan bangunan gedung.

Dengan adanya IMB dapat mewujudkan tata lingkungan yang teratur, sehingga terjadi keserasian antara lingkungan dan manusia selaku pengguna lahan. Banyak bangunanbangunan yang tidak memiliki izin mendirikan bangunan yang dibongkar, karena dibangun diatas lahan yang tidak boleh digunakan untuk mendirikan bangunan.

Kegunaan dari izin mendirikan bangunan:

1) Mendukung pelaksanaan pembangunan agar sesuai dengan rancangan teknis dan tata ruang yang telah direncanakan di suatu daerah.

2) Memudahkan pengawasan penggunaan bangunan, baik secara fungsimaupun dari segi estetika lingkungan

3) Mendapatkan kepastian hukum atas bangunan yang dimiliki

4) Dapat memudahkan dalam kepengurusan beberapa kegiatan

5) Menunjang kelangsungan pembangunan daerah melalui peningkatan pendapatan asli daerah.

\section{Metode Delphi}

Menurut Dunn (1994) secara umum, prinsip dasar Delphi adalah :
1) Anonimitas: para pakar yang memberikan pendapat tidak saling mengenal (dirahasiakan)

2) Iterasi: penilaian oleh para pakar dihimpun dan dikomunikasikan kembali dalam dua putaran atau lebih, sehingga berlangsung proses belajar sosial dan dimungkinkan berubahnya penilaian awal

3) Tanggapan balik yang terkontrol: pengkomunikasian penilaian dilakukan dalam bentuk rangkuman jawaban terhadap kuisioner

4) Jawaban statistik: rangkuman dari jawaban setiap orang disampaikan dalam bentuk ukuran tendensi sentral: distribusi frekuensi

5) Konsensus pakar: kesepakatan opini dari suatu kasus (hasil akhir)

\section{METODE PENELITIAN}

Berdasarkan masalah dan tujuan penelitian maka peneliti menggolongkan penelitian ini ke dalam penelitian kuantilatif. Jenis penelitian ini jenis penelitian campuran dengan menggunakan penelitian kuantitatif dan kualitatif.

Jenis data dalam yang digunakan adalah data primer dan data sekunder. Adapun data yang digunakan dalam penelitian ini yaitu Data lahan advice planning tahun 2014-2016, Data bangunan baru tidak memiliki IMB terbaru, Peta administrasi wilayah kota Bukittinggi menurut Rencana Tata Ruang Wilayah (RTRW) tahun 2011 dari Dinas Pekerjaan Umum Bidang Tata Ruang kota Bukittinggi. populasinya adalah semua pemilik bangunan yang mengurus advice planning tahun 2014-2016 yang tidak memiliki izin mendirikan bangunan sebanyak 285 orang pemilik bangunan.ditentukan sampel dengan rumus slovin terdapat 74 bangunan yang menjadi sampel penelitian. Dari 
74 bangunan setelah dilakukan penelitian terdapat 25 sampel bangunan.

Metode ini menggunakan serangkaian kuesioner atau angket. Pengumpulan data yang dilakukan dalam penelitian ini dilakukan dengan observasi, wawancara, Mengumpulkan informasi sejenis, yang sejenis dibuat kesimpulan faktor dari Ronde 1 menjadi lebih rinci untuk membantu pengumpulan informasi menggunakan angket pada Ronde 2 .

\section{HASIL DAN PEMBAHASAN \\ Deskripsi Dan Analisis Data}

Permasalahan IMB di Kota Bukittinggi masih banyaknya pemilik bangunan gedung diberi peringatan tentang bangunanya yang belum memiliki izin mendirikan bangunan. Dengan hal ini perlu diketahui faktor utama yang menyebabkan pemilik bangunan gedung tidak mengurus Izin atas bangunan yang didirikan.

a) Faktor-Faktor Pemilik Bangunan Gedung tidak Memiliki Izin Mendirikan Bangunan

Berdasarkan Tahapan Pertama Menggunakan Metode Delphi.

$\begin{array}{rrr}\text { Pada tahapan } & \text { pertama, } \\ \text { pengambilan } & \text { data } & \text { dengan }\end{array}$ menggunakan kuesioner memakai format pertanyaan yang terbuka dan terarah, dimana responden diberi kebebasan untuk menuliskan faktorfaktor yang menjadi penyebab masyarakat tidak mengurus IMB, sedangkan menurut peraturan daerah yang berlaku IMB wajib diurus untuk setiap bangunan yang didirikan.

b) Penilaian Faktor-Faktor Pemilik Bangunan tidak Mengurus Izin Mendirikan Bangunan Berdasarkan Tahapan Kedua Menggunakan Metode Delphi
Berdasarkan hasil kuesioner tahap kedua, tentang penilaian responden untuk 9 kategori jawaban yang menurut mereka faktor-faktor yang paling menjadi penyebab pemilik bangunan gedung tidak mengurus izin mendirikan bangunan dapat dilihat pada tabel 2 .

Tabel 1. Skor nilai tahap kedua mengenai faktor-faktor pemilik bangunan tidak mengurus izin mendirikan bangunan di Kota Bukittinggi

\begin{tabular}{|c|c|c|c|}
\hline \multirow[t]{2}{*}{ No } & \multirow[t]{2}{*}{ Identifikasi Faktor } & \multicolumn{2}{|c|}{ Tahapan II } \\
\hline & & Skor & Rank \\
\hline 1 & $\begin{array}{ll}\text { Ketidak } & \text { pedulian } \\
\text { terhadap peraturan } \\
\text { daerah }\end{array}$ & 145 & 7 \\
\hline 2 & $\begin{array}{l}\text { Tidak tahu aturan } \\
\text { IMB }\end{array}$ & 103 & 2 \\
\hline 3 & $\begin{array}{lr}\text { Tidak } & \text { ada biaya } \\
\text { untuk } & \text { mengurus } \\
\text { IMB } & \end{array}$ & 93 & 1 \\
\hline 4 & $\begin{array}{l}\text { Pengurusan } \\
\text { lama }\end{array}$ & 111 & 4 \\
\hline 5 & $\begin{array}{ll}\text { Tidak } & \text { cukup } \\
\text { persyaratan } & \\
\text { administrasi } & \\
\end{array}$ & 113 & 3 \\
\hline 6 & $\begin{array}{l}\text { Bangunan sudah } \\
\text { lama di bangun }\end{array}$ & 135 & 6 \\
\hline 7 & $\begin{array}{l}\text { Informasi } \\
\text { pembebasan } \\
\text { pengurusan IMB }\end{array}$ & 161 & 9 \\
\hline 8 & $\begin{array}{l}\text { Kurangnya } \\
\text { pengawasan dari } \\
\text { pemerintah daerah }\end{array}$ & 150 & 7 \\
\hline 9 & $\begin{array}{lr}\text { Tidak } & \text { ada waktu } \\
\text { untuk } & \text { mengurus } \\
\text { IMB } & \end{array}$ & 114 & 5 \\
\hline
\end{tabular}

Berdasarkan hasil dari sampel tersebut, 5 faktor yang mempengaruhi ditetapkan dengan penentuan peringkat 1 sampai 5. Skor terendah dan perigkat pertama yaitu jawaban tidak ada biaya untuk mengurus IMB dengan perolehan skor sebanyak 84 sedangkan skor yang tertinggi yaitu kategori tidak ada waktu untuk mengurus IMB dan pengurusan IMB 
lama berada pada peringkat terakhir dengan perolehan skor sebanyak 114

c) Penilaian Faktor-Faktor Pemilik Bangunan tidak Mengurus Izin Mendirikan Bangunan Berdasarkan Tahapan Ketiga Menggunakan Metode Delphi

Hasil pemberian nilai, peneliti menentukan 1 faktor utama yang menjadi penyebab berdasarkan 5 kategori jawaban yang telah ditentukan peneliti yang di nilai oleh responden untuk mengetahui hasil penelitian pada tahapan kuisioner ketiga merupakan penjelasan dari lampiran 4, dapat dilihat dari tabel 3.

Tabel 2. Skor nilai tahap ketiga mengenai faktor-faktor pemilik bangunan tidak mengurus izin mendirikan bangunan di Kota Bukittinggi

\begin{tabular}{|c|c|c|c|}
\hline \multirow[t]{2}{*}{ No } & \multirow{2}{*}{$\begin{array}{c}\text { Identifikasi } \\
\text { Faktor }\end{array}$} & \multicolumn{2}{|c|}{ Tahapan III } \\
\hline & & Skor & Rank \\
\hline 1 & $\begin{array}{l}\text { Tidak tahu aturan } \\
\text { IMB }\end{array}$ & 68 & 2 \\
\hline 2 & $\begin{array}{lr}\text { Tidak } & \text { ada biaya } \\
\text { untuk } & \text { mengurus } \\
\text { IMB } & \end{array}$ & 60 & 1 \\
\hline 3 & $\begin{array}{l}\text { Pengurusan IMB } \\
\text { lama }\end{array}$ & 83 & 4 \\
\hline 4 & $\begin{array}{l}\text { Tidak cukup } \\
\text { persyaratan } \\
\text { administrasi }\end{array}$ & 84 & 3 \\
\hline 5 & $\begin{array}{l}\text { Tidak ada waktu } \\
\text { untuk mengurus } \\
\text { IMB }\end{array}$ & 81 & 5 \\
\hline
\end{tabular}

Tabel 2. diketahui hasil seleksi penentuan jawaban pada tahapan III ditentukan berdasarkan peringkat menurut skornya masing-masing. Hasil dari tabel 2. diperoleh peringkat pertama yaitu tidak ada biaya untuk mengurus IMB dengan perolehan skor 60. Peringkat 2 yaitu tidak tahu aturan IMB dengan perolehan skor sebanyak 68. Peringkat 3 yaitu tidak cukup persyaratan administrasi dengan perolehan skor 81 . Peringkat 4 yaitu IMB faktor pengurusan IMB lama dan sulitnya prosedur dengan perolehan skor 83 sedangkan peringkat 5 atau terakhir yaitu tidak ada waktu untuk mengurus dengan perolehan skor 84 .

Tabel 3. Nilai mean dan median berdasarkan hasil perhitungan pengolahan data ronde 2 dan 3 metode Delphi tentang faktor-faktor pemilik bangunan tidak mengurus izin mendirikan bangunan di Kota Bukittinggi

\begin{tabular}{|c|c|c|}
\hline Responden & Ronde 2 & Ronde 3 \\
\hline 1 & 1 & 1 \\
\hline 2 & 1 & 1 \\
\hline 3 & 2 & 2 \\
\hline 4 & 8 & 4 \\
\hline 5 & 3 & 2 \\
\hline 6 & 2 & 2 \\
\hline 7 & 6 & 4 \\
\hline 8 & 8 & 4 \\
\hline 9 & 5 & 2 \\
\hline 10 & 1 & 1 \\
\hline 11 & 2 & 2 \\
\hline 12 & 5 & 4 \\
\hline 13 & 1 & 1 \\
\hline 14 & 4 & 2 \\
\hline 15 & 6 & 4 \\
\hline 16 & 8 & 5 \\
\hline 17 & 1 & 1 \\
\hline 18 & 8 & 4 \\
\hline 19 & 3 & 2 \\
\hline 20 & 2 & 1 \\
\hline 21 & 4 & 3 \\
\hline 22 & 8 & 4 \\
\hline 23 & 2 & 2 \\
\hline 24 & 1 & 1 \\
\hline 25 & 1 & 1 \\
\hline Jumlah & 93 & 60 \\
\hline Median (Me) & 3 & 2 \\
\hline Rata-rata (x) & 3 & 2 \\
\hline
\end{tabular}

Tabel 4. Frekuensi hasil perhitungan pengolahan data ronde 2 dan 3 metode Delphi tentang faktor-faktor pemilik bangunan tidak mengurus izin mendirikan bangunan di Kota Bukittinggi 


\begin{tabular}{|c|c|c|}
\hline \multirow{2}{*}{ Ronde 1 } & Ronde 2 & Ronde 1 \\
\cline { 2 - 3 } & F & f \\
\hline a (1) & 7 & - \\
\hline b (2) & 5 & 8 \\
\hline c (3) & 2 & 8 \\
\hline d (4) & 2 & 1 \\
\hline e (5) & 2 & 7 \\
\hline f (6) & 2 & - \\
\hline g (7) & 0 & - \\
\hline h (8) & 5 & - \\
\hline i (9) & 0 & 1 \\
\hline & 25 & 25 \\
\hline
\end{tabular}

Ronde ketiga para pemilik bangunan juga diberi nilai sebelumnya, sama dengan ronde 2 tetapi sudah lebih ringkas. Hasil dari ronde ke tiga menunjukkan bahwa rata-rata dan median dari hasil perhitungan nilai 2.Dengan hal ini lebih dipertegas kembali oleh adanya perhitungan tersebut bahwa biaya menjadi pertimbangan pemilik bangunan tidak mengurus izin mendirikan bangunan. Hal ini dapat diketahui bahwa faktor utama yag menjadi penyebab pemilik bangunan tidak mengurus IMB karena tidak ada biaya untuk mengurus IMB.

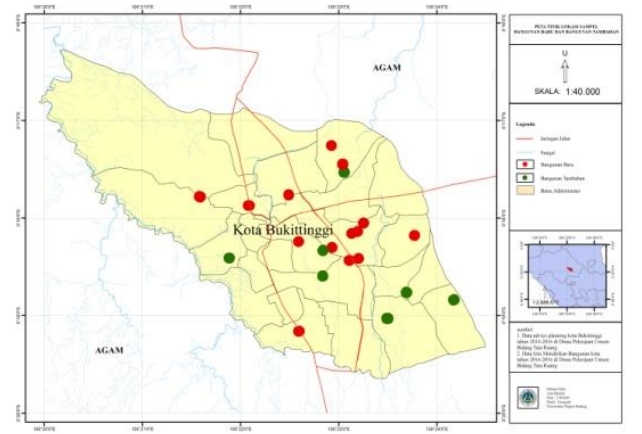

Gambar 1. Lokasi Penelitian

d) Penilaian instansi

faktor-faktor mempengaruhi

terhadap yang pemilik bangunan tidak mengurus izin mendirikan bangunan

1) faktor biaya

Berdasarkan hasil observasi yang penulis lakukan tanggal 19 juni 2017 dan 20 juni 2017, maka penulis dapat menyimpulkan bahwa instansi pemerintah terkait dengan pengurusan IMB telah menetapkan restribusi IMB sesuai dengan peraturan daerah yang berlaku di Kota Bukittinggi. Hal ini dilakukan untuk meringankan masyarakat yang mengeluh tentang biaya izin mendirikan bangunan.

2) faktor ketidaktahuan

Berdasarkan hasil observasi yang penulis lakukan maka penulis dapat simpulkan bahwa instansi pemerntah terkat dengan izin mendirikan bangunan sudah melakukan sosialisasi dan penginformasian yang telah dilakkan dinas perizinan, telah disediakan brosur ataupun papan peringatan setiap kelurahan untuk izin mendirirkan bangunan tersebut, tetapi masih ditemukan pemilik bangunan yang tidak menahami arti dan manfaat izin mendirikan bangunan.

3) faktor persyaratan administrasi

Berdasarkan hasil observasi yang penulis lakukan maka penulis dapat simpulkan bahwa Persyaratanpersyaratan administrasi yang diajukan d8inas perizinan dan tidak terpenuhi oleh pemilik bangunan tidak diberikan keringanan hanya diberi penambahan waktu untuk melengkapi berkas tersebut. Hal ini dilakukan untuk semua bangunan gedung yang ada di Kota Bukittinggi.

e) Penilaian perhitungan biaya sebagai faktor utama pemilik bangunan tidak mengurus Izin mendirikan bangunan

Dari hasil perhitungan restribusi IMB yang harus dibayarkan oleh responden pemilik bangunan gedung kepada dinas perizinan yang dijadikan sampel dapat diketahui bahwa restribusi IMB yang telah dihitung harganya lebih kecil dari harga biaya kira-kira pembuatan bangunan yang 
didirikan. pemilik bangunan tidak memiliki kesadaran untuk mengurus perizinan atas bangunan yang didirikan, pemilik bangunan belum memiliki kesiapan dalam membayar restribusi IMB, padahal dalam membayar restribusi IMB lebih kecil dari biaya pembuatan bangunan. Selain itu ketakukan pemilik bangunan gedung dalam pembayaran pajak. Jika bangunan di dirikan maka pajak akan bertambah sesuai perhitungan dinas perpajakan. Dari hal tersebut membuat banyak pemilik bangunan tidak mengurus izin mendiikan bangunan karena ketakutan dalam membayar biaya yang bersangkutan dengan pemeritah.

Kemahalan biaya IMB

disebabkan alasan sebagai berikut:

a. adanya persepsi masyarakat yang mengungkapkan bahwa pengurusan IMB mahal, padahal untuk pengurusan dan biaya restribusi telah ditetapkan berdasarkan peraturan yang berlaku

b. ketidak mampuan para pemilik bangunan dalam mengurus izin karena pendapatan yang rendah, untuk bangunan yang didirikan ada yang didapat dari bantuan yang diperoleh dari kelurahan dan ada bangunan yang didirikan secara berangsur-angsur sehingga menjadi bangunan yang layak untuk dihuni.

\section{f) Kendala pengurusan IMB oleh pemerintah daerah}

1) kurangnya sosialisasi terhadap peraturan daerah tentang IMB kepada masyarakat. Sosialisasi hanya dilakukan melalui papan peringatan untuk mengurus izin mendirikan bangunan, seharusnya ada sosialisasi langsung pada setiap kelurahan untuk mematuhi peraturan tersebut.

2) Tidak ada ketepatan waktu yang diberikan dalam kepengurusan tentunya dan harus hal ini sangat penting agar mendapat perhatian bagi pemerintah.

3) Masih kurangnya pengawas di lapangan sehingga proses pekerjaan mendirikan bangunan memakan waktu yang lama.

4) Kurangnya pengawasan di lapangan sehingga masih ditemukan bangunan-bangunan baru tidak memiliki izin

\section{g) Kendala pengurusan IMB oleh} pemilik bangunan

1) Masyarakat tidak paham mengenai prosedur mulai dari mengajukan permohonan surat izin sampai terbitnya surat izin mendirikan bangunan

2) Ketidak siapan masyarakat pengurus IMB untuk membayar restibusi IMB, sedangkan syaratnya harus melunasi restribusi IMB

3) Kesengajaan masyarakat untuk melanggar aturan-aturan yang berlaku dari pemerintah daerah untuk melakukan perizinan terkait dengan bangunan yang dibangun

4) Kurangnya kesadaran masyarakat yang tergolong golongan menengah ke atas untuk mengurus IMB dengan keluhan tidak ada biaya. Dalam hal ini instansi harus bertindak tegas apabila dilapangan masih ditemukan masyarakat yang tidak memiliki kesadaran.

\section{KESIMPULAN DAN SARAN}

a) Kesimpulan 
Kesimpulan dari penelitian ini adalah terdapat 5 faktor yang menjadi penyebab pemilik bangunan gedung tidak mengurus izin mendirikan bangunan di Kota Bukittinggi yaitu tidak tahu aturan IMB, tidak ada biaya. untuk mengurus IMB, pengurusan IMB lama, tidak cukup persyaratan administrasi dan tidak ada waktu untuk mengurus IMB. Adapun factor yang paling mejadi penyebab adalah tidak ada biaya untuk mengurus IMB menjadi alasan terbanyak oleh pemilik bangunan gedung

b) Saran

Adapun saran yang diberikan dalam penelitian ini yaitu sebagai berikut:

1. Pemilik bangunan gedung harus mempertimbangkan kembali saat bangunan tanpa izin didirikan, hal ini di sarankan agar terpatuhinya aturan-aturan yang telah dibuat oleh pemerintah daerah.
2. Pemilik bangunan gedung haruslah peduli terhadap peraturan daerah.

3. Peran pemerintah sangat diperlukan untuk memantau kembali bangunan-bnagunan yang didirikan tanpa izin dan pemerintah juga berperan untuk menginformasikan dan memsosialisasikan kembali kepada pemilik bangunan gedung, agar pemilik bangunan gedung tahu pentingnya mengurus izin mendirikan bangunan.

\section{DAFTAR PUSTAKA}

Dunn, W. N. (1994). Public Policy Analsis. United States Of America: Prentice-

Rahmadi, T. (2011). Hukum Lingkungan Di Indonesia. Jakarta: Rajawali Pers.

Peraturan Menteri No. 24 Tahun 2006 Tentang Pedoman Teknis Izin Mendirikan Bangunan

Peraturan Pemerintah RI no. 36 tahun 2005, Tentang Izin Mendirikan Bangunan Gedung 